\title{
Combustion stability of dual fuel engine powered by diesel-ethanol fuels
}

The paper presents result of combustion stability assessment of dual fuel engine. The authors analyzed results of co-combustion of diesel fuel with alcohol in terms of combustion stability. The comparative analysis of both the operational parameters of the engine and the IMEP, as the parameters determining the stability of the combustion process, were carried out. It was analyzed, among others values of the $C O V_{I M E P}$ coefficient, the spread of the maximum pressure value, the angle of the position of maximum pressure and the probability density distribution of the IMEP. The experimental investigation was conducted on 1-cylinder air cooled compression ignition engine. The test engine operated with constant rpm equal to $1500 \mathrm{rpm}$ and constant angle of start of diesel fuel injection. The engine was operated with ethanol up to 50\% of its energy fraction. The influence of ethanol on ignition delay time spread and end of combustion process was evaluated. It turns out that the share of ethanol does not adversely affect the stability of ignition.

Key words: combustion stability, heat release, dual fuel, ignition delay, combustion phases

\section{Introduction}

Diesel engines are widely used to power engineering devices for its good durability, thermal efficiency and specific power output. On the other hand, these engines are major contributors of air pollutant emission such as carbon monoxide $(\mathrm{CO})$ and nitrogen oxides $\left(\mathrm{NO}_{\mathrm{x}}\right)[1,2]$.

Due to stricter emissions standards for diesel engines with regards to $\mathrm{NO}_{\mathrm{x}}$ and $\mathrm{CO}_{2}$ emission and fuel consumption is growing concerns on the applicability of clean energy technologies [3]. Most of investigations showed that using alcohols in diesel engines can reduce emission of hydrocarbon $(\mathrm{HC})$, carbon monoxide $(\mathrm{CO})$ and particulate matter (PM) emissions, but nitrogen oxide $\left(\mathrm{NO}_{\mathrm{x}}\right)$ emission increases [4-6]. The oxygen content of alcohols structure is an important factor in the $\mathrm{NO}_{\mathrm{x}}$ formation, because it causes to high local temperatures due to excess hydrocarbon oxidation. The increased oxygen levels increase the maximum temperature during the combustion, and increase $\mathrm{NO}_{\mathrm{x}}$ formation [7-10].

Co-combustion of diesel fuel with alcohol can be made by two different combustion systems. The first one is to prepare a blend of diesel fuel with alcohol and bring the blend to the engine, using a typical supply system for the diesel engine. The main disadvantage of this combustion system is problem with stability of fuels blend and separation of fuels and lack of flexibility on the ratio of diesel/alcohol. The second one is a dual-fuel technology in which alcohol is supplied by injection to intake port of IC engine. Into the engine cylinder is delivered, nearly homogeneous, air-alcohol combustible mixture. The ignition is realized by the injected dose of diesel fuel before TDC. This technology requires the additional injection system, the separate fuel tank, lines and controls system $[11,12]$.

Ethanol fuel is one of the most interesting fuel among alcoholic fuels due to its relatively high value of LHV, lover value of her of evaporation than methanol and its availability. Ethanol is a biomass based renewable energy source, which can be produced with relatively low cost.

Ethanol can be produced using two methods: from petroleum materials (crude oil, natural gas or coal) using the chemical processes or from plant-based materials through alcohol fermentation of sugars such as glucose contained in biomass. Ethanol can be produced from any plants which contains of sugar or other components which can be converted into sugar, such as starch or cellulose in the fermentation, distillation and dehydration process [13]. Ethanol for a long time was considered as curious engine fuel. At first ethanol was associated with spark-ignition engines. From many years' ethanol is used as a fuel for compression ignition engines $[14,15]$.

Lee et al. [16] presented effects of varying the ethanol substitution ratio on engine performance and emissions under the dual-fuel combustion condition under various load conditions. The test engine was a heavy-duty singlecylinder diesel engine with two direct injectors. Engine speed was fixed at $1000 \mathrm{rpm}$ and the load condition was varied for an indicated mean effective pressure (IMEP) ranging from 0.2 to $0.8 \mathrm{MPa}$. The ratio of ethanol to the total input energy was controlled from zero to nearly $50 \%$ of the input energy. The $\mathrm{NO}_{\mathrm{x}}$ and $\mathrm{PM}$ emissions decreased with increasing ethanol substitution and the mean size of the PM emissions decreased. For the mid-load condition (IMEP 0.6 MPa), the substitution was increased to $63 \%$, but for low and high loads, higher ethanol fractions could not be used because of insufficient ignition energy at low loads and sharp increment of the in-cylinder pressure under high loads. Pedrozo et al. [17] presented results of investigation of dual-fuel combustion in CI engine carried out from low to full engine load with the same engine hardware and identical operating conditions to those of the baseline engine. The experiments were executed on a single cylinder heavyduty diesel engine at a constant speed of $1200 \mathrm{rpm}$ and various steady-state loads between 0.3 and $2.4 \mathrm{MPa}$ net indicated mean effective pressure (IMEP). Ethanol was port fuel injected while diesel was direct injected using a high pressure common rail injection system. The start of diesel injection was optimized for the maximum net indicated efficiency in both combustion modes. Varied ethanol energy fractions and different diesel injection strategies were required to control the in-cylinder pressure rise rate and achieve highly efficient and clean dual-fuel operation. In terms of performance, dual-fuel combustion attained higher net indicated efficiency than the conventional diesel combustion mode from 0.6 to $2.4 \mathrm{MPa}$ IMEP, with a maximum 
value of $47.2 \%$ at $1.2 \mathrm{MPa}$ IMEP. The comparison also shows the use of ethanol resulted in $26 \%$ to $90 \%$ lower nitrogen oxides $\left(\mathrm{NO}_{\mathrm{x}}\right)$ emissions than the conventional diesel combustion operation. At the lowest engine load of $0.3 \mathrm{MPa}$ IMEP, the dual-fuel operation led to simultaneous low $\mathrm{NO}_{\mathrm{x}}$ and soot emissions at the expense of a relatively low net indicated efficiency of $38.9 \%$. In particular, the reduction in $\mathrm{NO}_{\mathrm{x}}$ emissions introduced by the utilization of ethanol has the potential to decrease the engine running costs via lower consumption of aqueous urea solution in the selective catalyst reduction system. Moreover, the dual-fuel combustion with a low carbon fuel such as ethanol is an effective means of decreasing the use of fossil fuel and associated greenhouse gas emissions. Dong et al. [18] stated that in dual-fuel engines, the fuel stratification produced by direct in-cylinder blending of port injected and direct injected fuels is important for combustion and emission control, while the fuel stratification could be influenced by port fuel proportion, direct injection strategy as well as geometry of direct injector. Authors investigated ethanol/diesel dual-fuel engine. They studied influence incylinder fuel stratification as well as auto-ignition and combustion process. The equivalence ratio of premixed ethanol, maximum local equivalence ratio and fuel concentration gradients in radial and circumferential directions of the cylinder were used to evaluate the fuel stratification. Under the tested dual-fuel conditions, the results showed that auto-ignition was more likely to first occur in regions with mixture near stoichiometric ratio, rather than regions with mixtures exhibiting highest fuel reactivity. As a consequence, larger equivalence ratio of premixed ethanol could prolong ignition delay of in-cylinder charge by reducing the fuel reactivity of regions where ignition kernels first occurred. The experimental results showed that with reduced nozzle holes, the peak pressure and heat release rate of dual-fuel operation could be decreased. This was mainly because fewer nozzle holes could result in fuel stratification in both circumferential and radial directions, thus the development of combustion zone was slowed down and consequently the heat release rate was decreased [18]. Rakopoulos et al. [19] studied the impact of using n-butanol or ethanol in blends with diesel fuel (extenders) on combustion, cyclic irregularity, and exhaust emissions trade-off (balance). Experiments were conducted at two speeds and three loads in a fully-instrumented, six-cylinder, fourstroke, heavy-duty direct injection (HDDI), turbocharged, diesel engine. Authors stated that the ignition delay was increased for the n-butanol or ethanol diesel blends compared to the neat diesel cases, more so for the ethanol ones. The HRR traces of the n-butanol or ethanol diesel blends were delayed with respect to the neat diesel ones, more so for the ethanol ones. The cycle-to-cycle variations of the maximum pressure showed that there were small differences among the neat diesel fuel case and its two biofuels blends tested, inside acceptable limits. The little higher values for the ethanol and n-butanol diesel fuel blends signify that this may be due to their higher ignition delay values [19].

There are also works on the evaluation of combustion stability. Yao et al. presented results of investigates on cycle-to-cycle variation of dieseline fueled PPCI engine and introduces a closed-loop control method based on incylinder pressure sensor. Experiments were performed on a four-cylinder compression ignition engine. Results showed that $\mathrm{p}_{\max }$ and $\theta_{\mathrm{pmax}}$ (crank angle where occurs) cannot be properly identified by the control system. Thus, COV coefficient of variation) of $\mathrm{p}_{\max }$ and $\theta_{\mathrm{pmax}}$ cannot reflect the real combustion fluctuation level. $\operatorname{COV}_{\text {IMEP }}$ can be chosen as the combustion stability indicator to evaluate cycle-to-cycle variation. An et al. [20] investigated the sensitivity of combustion stability to the intake air temperature for partially premixed combustion (PPC). The experiments were carried out in a full view optical engine at low load condition. The results showed that the lower intake temperature could be used for achieving better combustion stability at low load condition along with the retarded CA50, the lower maximum in-cylinder pressure, and the higher IMEP. $70^{\circ} \mathrm{C}$ was the lower limit of intake temperature to achieve stable PPC operation with the single-injection strategy. The same trend of the combustion characteristics with respect to the start of injection timing was confirmed at various intake temperatures [21]. Zhou et al. studies gasoline compression ignition (GCI) engine as one of the most promising combustion concepts to maintain low pollutant emissions and high efficiency. However, low load combustion stability and firing in cold-start operations are two major challenges for GCI combustion. Strategies including negative valve overlap (NVO), advanced injection strategies, fuel reforming, and intake preheating have been proposed in order to solve these difficulties. The results showed that start of injection (SOI) during the intake stroke yields the best fuel economy, and injection during the compression stroke has the potential to extend the low load limit.

In presented work authors have attempted to assessment of combustion stability of co-combustion process of diesel fuel with ethanol in dual fuel compression ignition engine. The research concerned the analysis of the combustion process and the analysis of non-repeatability for set of subsequent engine operation cycles. The analysis was made for heat release rate, combustion stages and combustion stability.

\section{Methods}

\subsection{Experimental test stand}

The researches ware carried out on the compression ignition engine operated with constant rotational speed of $1500 \mathrm{rpm}$. It was one-cylinder air cooled, naturally aspired, direct injection compression ignition engine. This engine was modernized to work as dual fuel engine. It was equipped with the independent port fuel injection system. Ethanol was injected in the intake manifold at 3 bar pressure and the value of the fuel dose was determined by the time of opening the injector. The injection system was equipped with an electronic control system connected with the signal of the crankshaft position.

Test engine operated with constant angle of beginning of biodiesel fuel injection equal to $23 \mathrm{deg}$ before TDC. The test bed is presented in Fig. 3. The main engine parameters are presented in Table 1.

The experimental studies were carried out on the test stand included elements: 
- 1CA90 engine adapted for operating as a dual fuel engine,

- data acquisition system,

- exhaust gas analyzer: THC, $\mathrm{CO}, \mathrm{CO}_{2}, \mathrm{O}_{2}-$ Bosch BEA 350 (THC: range 0-9999 ppm vol. accuracy: $12 \mathrm{ppm}$ vol.; $\mathrm{NO}_{\mathrm{x}}$ : range 0-5000 ppm accuracy: 10 ppm.; CO: range $0-10 \%$ vol. accuracy: $0.06 \%$ vol.; $\mathrm{CO}_{2}$ : range 0 $18 \%$ vol. accuracy: $0.4 \%$ vol.; $\mathrm{O}_{2}$ : range $0-22 \%$ vol. accuracy: $0.1 \%$ vol.; $\lambda$ : range $0.5-9.999$ accuracy: 0.01 ).

The digital measurement system for data acquisition:

- piezoelectric pressure transducer, Kistler 6061 SN 298131, sensitivity: $\pm 0.5 \%$,

- charge amplifier, Kistler 5011B, the linearity of FS < $\pm 0.05 \%$,

- data acquisition module, Measurement Computing USB-1608HS - 16 bits resolution, sampling frequency $20 \mathrm{kHz}$,

- the CA encoder, resolution 360 pulses/rev, software for digital recording and analysis of the frequency signals [22].

Table 1. Main engine parameters

\begin{tabular}{|l|c|c|}
\hline Parameter & Value & Unit \\
\hline Number of cylinders & 1 & - \\
\hline Displacement volume & 0.573 & $\mathrm{dm}^{3}$ \\
\hline Bore & 90 & $\mathrm{~mm}$ \\
\hline Stroke & 90 & $\mathrm{~mm}$ \\
\hline Compression ratio & $17: 1$ & - \\
\hline Crankshaft rotational speed & 1500 & $\mathrm{rpm}$ \\
\hline Injection pressure & 21 & $\mathrm{MPa}$ \\
\hline Injection timing & 23 & $\mathrm{deg} \mathrm{bTDC}$ \\
\hline Maximum rated power & 7.4 & $\mathrm{~kW}$ \\
\hline
\end{tabular}

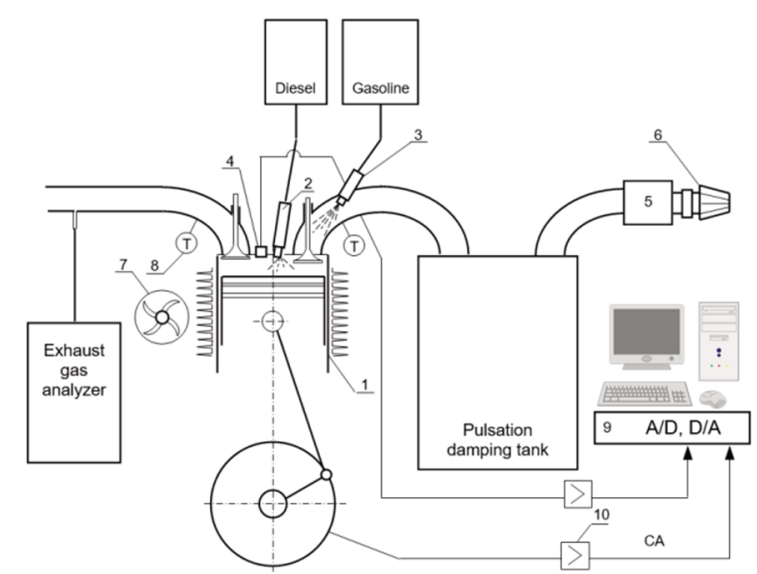

Fig. 1. Diagram of the experimental setup: 1 - engine, 2 - diesel fuel injector, 3 - ethanol fuel injector, 4 - in cylinder pressure sensor, 5 intake air flowmeter, 6 - air filter, 7 - cooling fan, 8 - exhaust gases temperature sensor, 9 - PC with data acquisition system, 10 - crank angle sensor

In Table 2 are presented fuels properties. The diesel fuel $\left(\mathrm{C}_{14} \mathrm{H}_{30}\right)$ was commercial fuel provided by the Polish Refinery and used commonly to feed diesel engines in cars. The fuel is a mixture of liquid hydrocarbons obtained through crude oil distillation. In the case of the diesel fuel, one of the important parameters is cetane number that denotes auto-ignition capabilities of the fuel. Ethanol $\left(\mathrm{C}_{2} \mathrm{H}_{5} \mathrm{OH}\right)$ is an alcohol with two carbon atoms in its structure. This fuel is obtained through processing of biological matter. Therefore, it can be considered a renewable energy source. This alcohol is numbered among strongly oxygenated alcohols and is characterized by a lower value of the LHV compared to conventional fuels. LHV of ethanol is lower in $40 \%$ compared to LHV of diesel's fuel. Therefore, to keep the constant energy dose, comparable to that contained in diesel fuel, bigger ethanol dose, in mass, should be provided. The high heat of vaporization $(840 \mathrm{~kJ} / \mathrm{kg}) \mathrm{im}-$ proves filling coefficient but increases of ignition delay which can cause the "hard" operation of the engine.

Table 2. Fuels properties $[4,9,10]$

\begin{tabular}{|l|c|c|}
\hline \multicolumn{1}{|c|}{ Properties } & Diesel & Ethanol \\
\hline Molecular formula & $\mathrm{C}_{14} \mathrm{H}_{30}$ & $\mathrm{C}_{2} \mathrm{H}_{5} \mathrm{OH}$ \\
\hline Molecular weight & $170-198$ & 46 \\
\hline Surface tension $\left(\mathrm{mN} / \mathrm{m} @ 15^{\circ} \mathrm{C}\right)$ & 26.9 & 21.78 \\
\hline Cetane number & 51 & 8 \\
\hline Lower heating value, $(\mathrm{MJ} / \mathrm{kg})$ & 41.7 & 26.9 \\
\hline Density at $20^{\circ} \mathrm{C}, \mathrm{kg} / \mathrm{m}^{3}$ & 856 & 789 \\
\hline Viscosity at $25^{\circ} \mathrm{C},(\mathrm{mPa} \mathrm{s})$ & 2.8 & 1.078 \\
\hline Heat of evaporation, $(\mathrm{kJ} / \mathrm{kg})$ & 260 & 918 \\
\hline Stoichiometric air fuel ratio & 14.7 & 9.06 \\
\hline Autoignition temperature, $\left({ }^{\circ} \mathrm{C}\right)$ & $300-340$ & 698 \\
\hline Flash point, $\left({ }^{\circ} \mathrm{C}\right)$ & 78 & 16.6 \\
\hline Hydrogen content, wt $\%$ & 13 & 13 \\
\hline Carbon content, wt $\%$ & 87 & 52.2 \\
\hline Oxygen content, wt $\%$ & 0 & 34.8 \\
\hline
\end{tabular}

\subsection{Calculation methodology}

The analysis of combustion process was conducted on the basis of heat release. The heat release rate was calculated based on the data of in-cylinder pressure regarding crank angle. Analysis was based on the first law of thermodynamics and the equation of state.

The unrepeatability of IMEP $\left(\mathrm{COV}_{\text {IMEP }}\right)$ was used as a parameter determined the cycle-by-cycle variations. The $\mathrm{COV}_{\text {IMEP }}$ is directly related to the investigated combustion stability. The $\mathrm{COV}_{\text {IMEP }}$ was calculated based on set of IMEP values from 200 following work cycles of the test engine.

$$
\mathrm{COV}_{\text {IMEP }}=\frac{\sigma_{\text {IMEP }}}{(\mathrm{IMEP})_{\text {mean }}} \cdot 100
$$

where: $\sigma_{\text {IMEP }}-$ standard deviation of IMEP.

Additionally, there are presented evaluation results of the probability density function of indicated mean effective pressure f(IMEP). This parameter can also be used as an indicator to assess the stability of operation of the internal combustion engine. The probability density of the indicated mean effective pressure:

$$
f(\operatorname{IMEP})=\frac{1}{\sigma_{\text {IMEP }} \sqrt{2 \pi}} \exp \left(\frac{-\left(\text { IMEP }_{\mathrm{i}}-\overline{\mathrm{IMEP}}\right)^{2}}{2 \sigma_{\text {IMEP }}^{2}}\right)
$$

The paper also presents the results of analysis of combustion stages for both combustion systems. The time of ignition delay and the duration of combustion were determined.

\section{Results and discussion}

In the paper are presented results of experimental investigation of co-combustion process of ethanol with diesel fuel using dual fuel technology. At each test point, the en- 
gine was fully warm up and its parameters were stabilized. The engine was run as long until the engine reached a constant temperature of the exhaust gases and invariable emission. The measurement system allowed for recording of the in-cylinder pressure with resolution of $1 \mathrm{deg}$ CA of 200 engine operating cycles. It was recorded simultaneously: rotational speed of engine, air and fuel consumption, air temperature, fuel temperature, exhaust gas temperature, ambient temperature and pressure.

The examinations were started from indication of the engine fueled with pure diesel as a reference. In the next stage of the research, the engine was powered with ethanol of an energy content: $11.3,18.5,24.8,33$ and 55\%. The tests were carried out at a constant angle of diesel injection start.

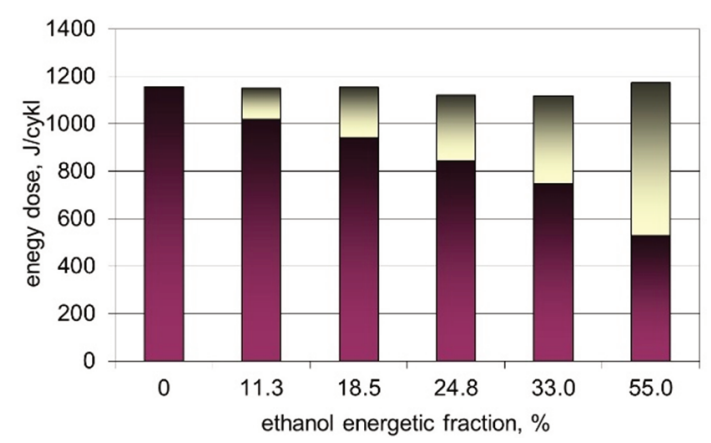

Fig. 2. The composition of the fuel dose

In Figure 2 are presented the fractions of energy dose delivered to the engine per one cycle. There are visible some variations in energy doses. It was due to uncertainty of power system. The variations were in range of $3 \%$ of energy content in fuel dose.

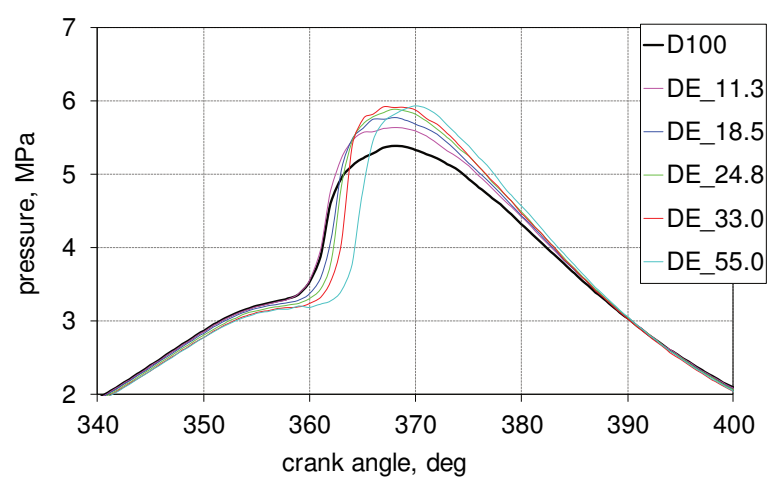

Fig 3. In-cylinder pressure

In Figure 3 are presented pressure changes for analyzed ethanol fractions. It is visible that with the increase in ethanol fraction in combustion process up to $33 \%$, obtained the increase in peak pressure. In addition, this delayed the combustion process. With $55 \%$ ethanol fraction, the combustion process has been deteriorated which was accompanied by the increase in SFC. There it is clearly visible cooling effect of evaporation ethanol during compression stroke.

In Figure 4 are presented heat release rate traces for analyzed ethanol fractions. Up to $20 \%$ of ethanol fraction noticed increase in peak value of HRR. It was due to an in- crease in ignition delay. After exceeding this ethanol content, a drop in the maximum value of HRR was observed and the combustion process was significantly extended.

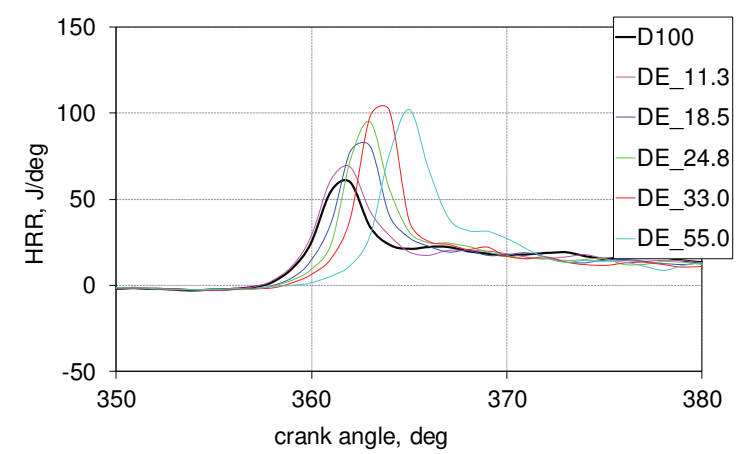

Fig 4. Heat release rate

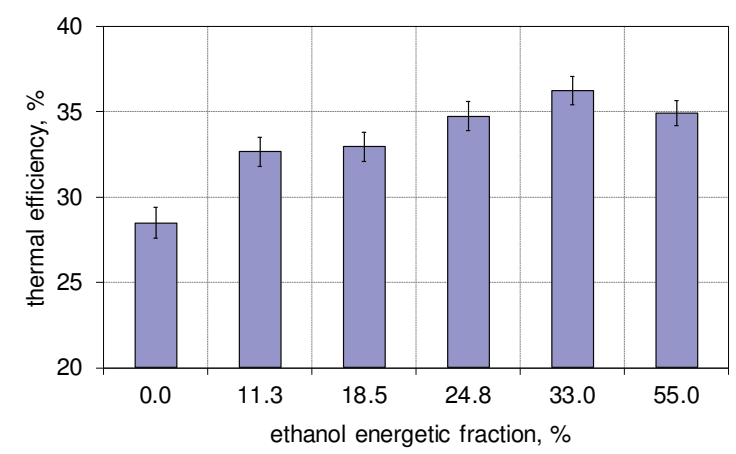

Fig. 5. Thermal efficiency

In Figure 5 are presented thermal efficiency values for analyzed ethanol fraction. It can be stated that with the increase in ethanol content in air-fuel mixture the thermal efficiency increased, it was up to $33 \%$ of ethanol fraction.

One of the fundamental problems in combustion engines domain, which has been researched from many years, is non-repeatability of work cycles. Researchers have studied the unrepeatability of engine cycles based on the analysis of combustion pressure [23].

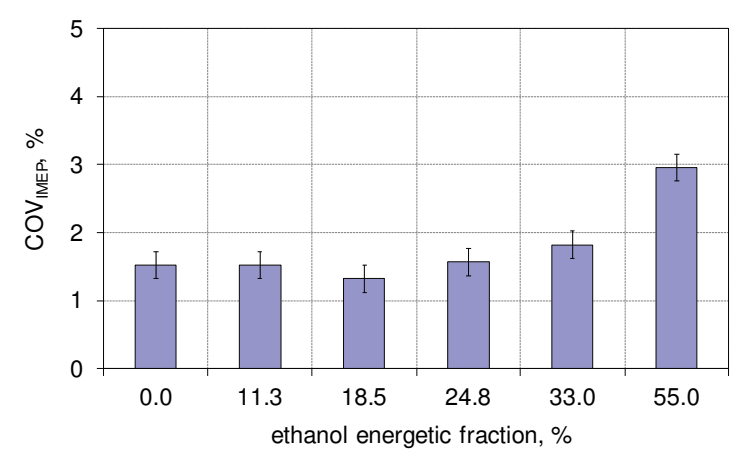

Fig. 6. Coefficient of cycle unrepeatability

In Figure 6 are presented results of cycle-to-cycle variations expressed by $\mathrm{COV}_{\text {IMEP }} \mathrm{COV}_{\text {IMEP }}$ is usually used as the indicator of combustion stability [24]. The threshold value of $\mathrm{COV}_{\text {IMEP }}$ equal to $5 \%$ is considered to provide engine stability [25]. It can be stated that up to $33 \%$ of ethanol content in combustion process the cycle-to-cycle 
variation were at constant level. For the last ethanol fraction it was observed the increase in $\mathrm{COV}_{\text {IMEP. It should be noted }}$ that for the entire analyzed range of ethanol fraction the $\mathrm{COV}_{\text {IMEP }}$ was below $5 \%$.

The combustion process in the internal combustion engine can be divided into two main phases. The first it is ignition delay and second the combustion duration. According to the classic ignition theory by Semenov, compression ignition is characterized by the initial period when the key role is played by chemical reactions before ignition. The physical phenomena which lead to ignition delay in compression ignition engines include decomposition of fuel into separate drops, heating and vaporization of drops and, finally diffusion of fuel vapor into the air. Speed of burning of the liquid fuel is determined by the speed of its vaporization and mixing of the sprayed fuels with air. The ignition delay is defined as the time between the start of diesel fuel injection and the crank angle of $10 \%$ heat release. This delay period consists of physical delay and chemical delay which occur simultaneously. In the physical delay takes place atomization, vaporization and mixing of air fuel, and in the chemical delay attributed pre-combustion reactions. Burn duration is calculated as the time from 10 to $90 \%$ of heat release.

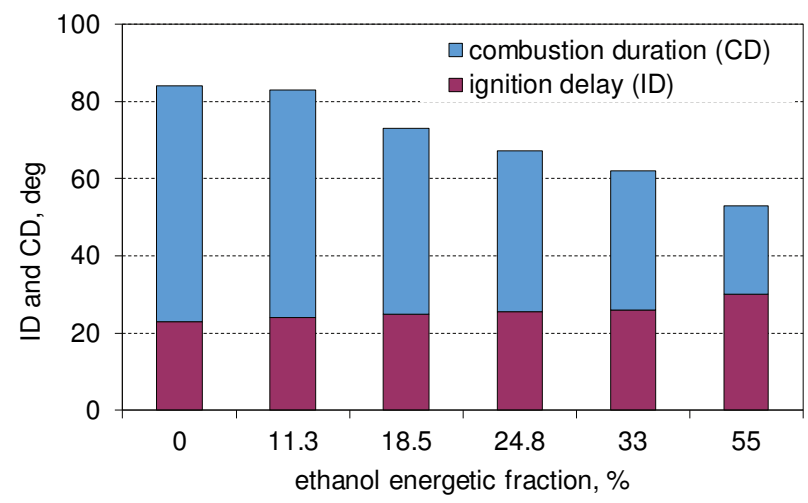

Fig 7. Stages of combustion process

In Figure 7 are presented the combustion stages for diesel/ethanol combustion. It can be stated that with the increase in ethanol content in combustion process the ignition delay increased which also was confirmed by other researchers [26, 27]. However, this increase is not too big. Compared to reference fuel combustion the increase in ID was from 23 to $30 \mathrm{deg}$. The increase was near to $25 \%$. In case of combustion duration with the increase in ethanol content the combustion time decreased. Compared to reference fuel combustion the increase in ID was from 61 to 23 deg. That the decrease in burning time was over $100 \%$. The study also assessed the uniqueness of the ignition delay and the combustion duration (Fig. 8). The ID and CD values shown in Fig. 8 are determined for the average MFB obtained from 200 consecutive engine cycles.

In Figure 8 is presented set of MFB curves for $55 \%$ of ethanol fraction in combustion process. There are indicated intervals of spread of ignition time (SOI) and spread of the end of combustion (SEC). The results of this analysis are presented in Fig. 9.

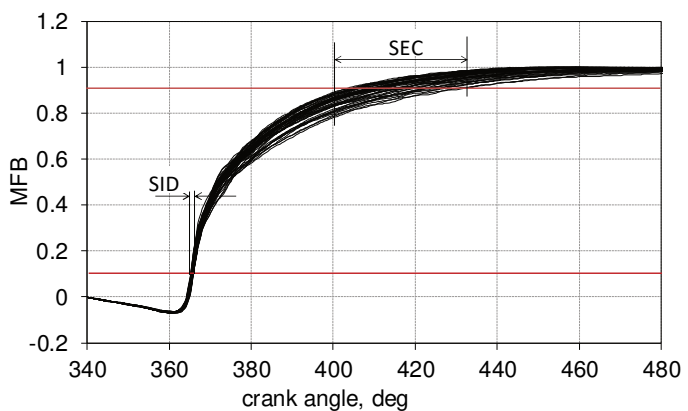

Fig. 8. Mass fraction burned for co-combustion of diesel fuels with ethanol (for $55 \%$ of ethanol fraction)

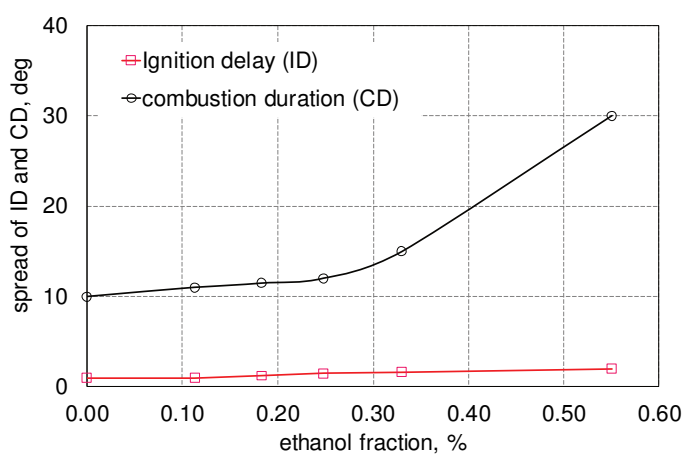

Fig. 9. Spread of ignition delay and combustion duration

In Figure 15 are presented results of spread estimation of MFB. It is directly connected with unrepeatability of combustion process in the IC engine. It can be stated that ethanol participation in combustion of fuels does not affect spread of ignition delay. The distribution of ID was within $2 \mathrm{deg}$ of CA. In case of spread of combustion duration with the increase in ethanol content this indicator was increased. After exceeding the $30 \%$ ethanol content noticed significant increase in this parameter. For 0.50 ethanol content noticed 3 -times higher value of spread of CD, and it was equal to30 deg of CA.

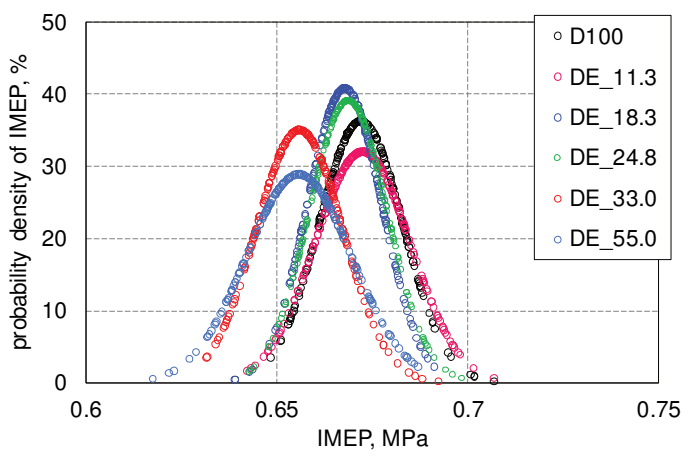

Fig. 10. Probability density of IMEP

In Figure 10 are presented results of assessment of probability density of IMEP. It is visible that for 0.30 ethanol energetic fraction noticed high combustion stability and spread of IMEP was not wider than for reference fuel combustion. After exceeding this ethanol fraction it was visible enlargement of spread of IMEP. 


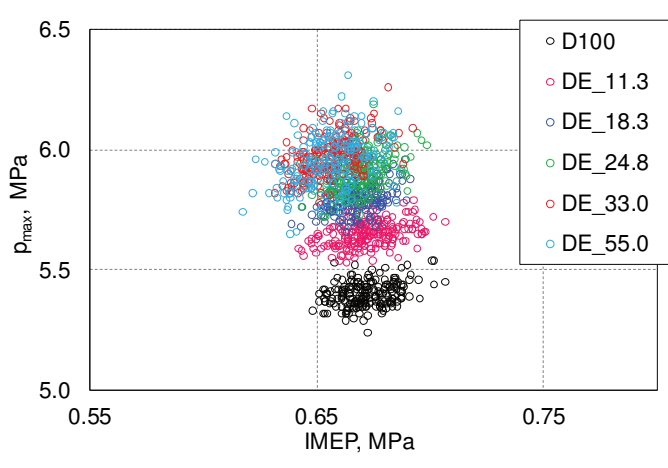

Fig. 11. Relationship of IMEP and $\mathrm{p}_{\max }$

In Figure 11 is presented relationship between IMEP and peak pressure value. It presented the correlation between the maximum combustion pressure and the indicated mean effective pressure for an engine powered by pure diesel fuel and a dual fuel engine for co-combustion of diesel with ethanol. It can be stated that with the increase in ethanol energetic fraction the peak pressure values increased. Additionally, with the increase in ethanol content increases the spread of these values.

\section{Conclusions}

Ethanol used to power IC engines reduce the use of fossil fuels. This study presents experimental results of a CI engine investigation with dual-fuel system, in which cocombustion of diesel with ethanol with energy content up to $55 \%$. The research included the analysis of the combustion process and the analysis of the non-repeatability of the subsequent engine operation cycles. On the basis of results were formed conclusions:

- ethanol used for co-combustion with diesel fuel causes an increase in compression ignition delay and increases the heat release rate and maximum combustion pressure values;

- up to $33 \%$ of ethanol content in combustion process the cycle-to-cycle variation were at constant level 1.5$1.8 \%$; for the maximal ethanol fraction it was observed the increase in $\mathrm{COV}_{\mathrm{IMEP}}$,

- with the increase in ethanol content in combustion process the ignition delay increased but combustion duration decreased;

- on the basis of the function of probability density of the IMEP, it can be stated that the increase in the percentage of ethanol fuel used for co-combustion with diesel does not worse ignition capabilities; the spread of ID was within 2 deg of CA;

- the spread of CD with the increase in ethanol content it was increased. After exceeding the $30 \%$ ethanol content noticed significant increase in this parameter. For 0.50 ethanol content noticed 3-times higher value of spread of $\mathrm{CD}$, and it was equal to $30 \mathrm{deg}$ of CA;

- with the increase in ethanol energetic fraction the peak pressure values and the spread of these values increased.

\section{Acknowledgements}

Research was financed by the Ministry of Science and Higher Education of Poland from the funds dedicated to scientific research No. BS/PB 1-103-3030/2017/P

\section{Nomenclature}

CA crank angle

CI compression ignition

CD combustion duration

ID ignition delay

IMEP indicated mean effective pressure

$\mathrm{COV}$ coefficient of variation
LHV lower heating value

DE diesel/ethanol

HRR heat release rate

IC internal combustion

MFB mass fraction burned

\section{Bibliography}

[1] SZABADOS, G., BERECZKY, Á., AJTAI, T., BOZÓKI, Z. Evaluation analysis of particulate relevant emission of a diesel engine running on fossil diesel and different biofuels. Energy. 2018, 161, 1139-1153. DOI:10.1016/j.energy.2018.07.154

[2] MERKISZ, J., WALIGÓRSKI, M. Strategy of the combustion process diagnosis in direct injection engines. Procedia Engineering. 2014, 96, 294-301. DOI:10.1016/j.proeng.2014. 12.141

[3] KUMAR, S., CHO, J.H., PARK, J., MOON, I. Advances in diesel-alcohol blends and their effects on the performance and emissions of diesel engines. Renewable and Sustainable Energy Reviews. 2013, 22, 46-72.

[4] JAMROZIK, A. The effect of the alcohol content in the fuel mixture on the performance and emissions of a direct injection diesel engine fueled with diesel-methanol and dieselethanol blends. Energ Convers Manage. 2017, 148, 461476.

[5] MERKISZ, J., FUĆ, P., LIJEWSKI, P., PIELECHA, J. Actual emissions from urban buses powered with diesel and gas engines. Transportation Research Procedia. 2016, 14, 3070-3078. DOI:10.1016/j.trpro.2016.05.452

[6] FAYYAZBAKHSH, A., PIROUZFAR, V. Comprehensive overview on diesel additives to reduce emissions, enhance fuel properties and improve engine performance. Renewable and Sustainable Energy Reviews. 2017, 74, 891-901. DOI:10.1016/j.rser.2017.03.046

[7] KUMAR, S., CHO, J.H., PARK, J., MOON, I. Advances in diesel-alcohol blends and their effects on the performance and emissions of diesel engines. Renewable and Sustainable Energy Reviews. 2013, 22, 46-72.

[8] TUTAK, W., JAMROZIK, A., GNATOWSKA, R. Combustion of different reactivity fuel mixture in a dual fuel engine. Therm Sci. 2018, 22(3), 1191-1203. DOI:10.2298/ TSCI170606299T.

[9] TUTAK, W. Bioethanol E85 as a fuel for dual fuel diesel engine. Energy Conversion and Management. 2014, 86, 3948. DOI: 10.1016/j.fuel.2017.04.021 
[10] TUTAK, W., LUKÁCS, K., SZWAJA, S., BERECZKY, Á. Alcohol-diesel fuel combustion in the compression ignition engine. Fuel. 2015, 154, 196-206.

[11] STELMASIAK, Z., MATYJASIK, M. Simulation of the combustion in a dual fuel engine with a divided pilot dose. Combustion Engines. 2012, 151(4), 43-54.

[12] MIKULSKI, M., BEKDEMIR, C. Understanding the role of low reactivity fuel stratification in a dual fuel RCCI engine A simulation study. Applied Energy. 2017, 191, 689-708. DOI: $10.1016 /$ j.apenergy.2017.01.080

[13] AYDIN, H., ILKILIÇ, C. Effect of ethanol blending with biodiesel on engine performance and exhaust emissions in a CI engine. Applied Thermal Engineering. 2010, 30, 11991204.

[14] STELMASIAK, Z., MATYJASIK, M. Exhaust emissions of dual fuel self-ignition engine with divided initial dose. Combustion Engines. 2013, 154(3), 944-952.

[15] HUNICZ, J., MIKULSKI, M. Investigation of the thermal effects of fuel injection into retained residuals in HCCI engine. Applied Energy. 2018, 228, 1966-1984. DOI:10.1016/ j.apenergy.2018.07.075

[16] JEONGWOO LEE, SUNYOUP LEE, SEOKHWAN LEE, Experimental investigation on the performance and emissions characteristics of ethanol/diesel dual-fuel combustion. Fuel. 2018, 220, 72-79.

[17] VINÍCIUS, B. PEDROZO, IAN MAY, WEI GUAN, HUA ZHAO. High efficiency ethanol-diesel dual-fuel combustion: A comparison against conventional diesel combustion from low to full engine load. Fuel. 2018, 230, 440-451.

[18] SHIJUN DONG, ZHAOWEN WANG, CAN YANG et al. Investigations on the effects of fuel stratification on autoignition and combustion process of an ethanol/diesel dualfuel engine. Applied Energy. 2018, 230, 19-30.

[19] RAKOPOULOS, C.D., RAKOPOULOS, D.C., KOSMADAKIS, G.M. et al. Experimental comparative assessment

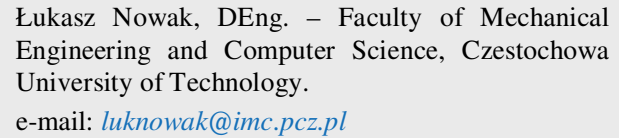

of butanol or ethanol diesel-fuel extenders impact on combustion features, cyclic irregularity, and regulated emissions balance in heavy-duty diesel engine. Energy. 2019, 174, 1145-1157.

[20] YANZHAO AN, VALLINAYAGAM RAMAN, QINGLONG TANG et al. Combustion stability study of partially premixed combustion with low-octane fuel at low engine load conditions. Applied Energy. 2019, 235, 56-67.

[21] LEI ZHOU, JIANXIONG HUA, HAIQIAO WEI, YIYONG HAN. An experimental investigation on low load combustion stability and cold-firing capacity of a gasoline compression ignition engine. Engineering. 2019, 5. DOI: 10.1016/ j.eng.2018.12.010

[22] GRUCA, M. Software for acquisition of internal combustion engine data. Journal of Kones. 2004, 11, 205-211.

[23] TUTAK, W., JAMROZIK, A., Characteristics of the flow field in the combustion chamber of the internal combustion test engine. Chemical and Process Engineering. 2011, 32(3), 203-214. DOI:10.2478/v10176-011-0016-4

[24] CHANGSHENG, YAO, YAODONG, HU, TIANYUAN, ZHOU et al. Combustion stability control of dieseline PPCI based on in-cylinder pressure signals. IFAC-PapersOnLine. 2016, 49-11, 333-339.

[25] Heywood J.B. Internal Combustion Engine Fundamentals. Mc Graw Hill, 2018.

[26] KUSZEWSKI, H. Experimental investigation of the autoignition properties of ethanol-biodiesel fuel blends. Fuel. 2019, 235, 1301-1308. DOI:10.1016/j.fuel.2018.08.146.

[27] KUSZEWSKI, H., JAWORSKI, A., USTRZYCKI, A. et al. Use of the constant volume combustion chamber to examine the properties of autoignition and derived cetane number of mixtures of diesel fuel and ethanol. Fuel. 2017, 200, 564575.

Wojciech Tutak, DSc., DEng. - Faculty of Mechanical Engineering and Computer Science, Czestochowa University of Technology. e-mail: tutak@imc.pcz.pl 